\title{
Article
}

\section{MICA*019 Allele and Soluble MICA as Biomarkers for Ankylosing Spondylitis in Taiwanese}

\author{
Chin-Man Wang ${ }^{1,+}$, Keng-Poo Tan ${ }^{2,+}$, Yeong-Jian Jan $\mathrm{Wu}^{2}{ }^{2}$, Jing-Chi Lin ${ }^{2}$, Jian-Wen Zheng ${ }^{2}$, Alice L. Yu ${ }^{3,4}(\mathbb{D}$, \\ Jian-Ming $\mathrm{Wu}^{5, \ddagger}$ and Ji-Yih Chen ${ }^{2, *, \ddagger}$
}

1 Department of Rehabilitation, Chang Gung Memorial Hospital, Chang Gung University College of Medicine, Taoyuan 33302, Taiwan; cmw1314@adm.cgmh.org.tw

2 Department of Medicine, Division of Allergy, Immunology and Rheumatology, Chang Gung Memorial Hospital, Chang Gung University College of Medicine, Taoyuan 33302, Taiwan; helentan.tw@yahoo.com.tw (K.-P.T.); yjwu1962@gmail.com (Y-J.J.W.); jingchilin@gmail.com (J.-C.L.); pqr780925@cgmh.org.tw (J.-W.Z.)

3 Institute of Stem Cell and Translational Cancer Research, Chang Gung Memorial Hospital at Linkou, Taoyuan 33375, Taiwan; a1yu@ucsd.edu

4 Department of Pediatrics, University of California, San Diego, CA 92103, USA

5 Department of Veterinary and Biomedical Sciences, Department of Medicine, University of Minnesota, Minneapolis, MN 55108, USA; jmwu@umn.edu

* Correspondence: jychen31@adm.cgmh.org.tw; Tel.: +886-3-328-1200 (ext. 2410); Fax: 886-3-3288-287

+ These auhors contributed equally to this paper.

$\ddagger \quad$ These auhors contributed equally to this paper.

Citation: Wang, C.-M.; Tan, K.-P.; Jan Wu, Y.J.; Lin, J.-C.; Zheng, J.-W.; Yu, A.L.; Wu, J.-M.; Chen, J.-Y. MICA*019 Allele and Soluble MICA as Biomarkers for Ankylosing Spondylitis in Taiwanese. J. Pers. Med. 2021, 11, 564. https://doi.org/10.3390/ jpm11060564

Academic Editor: David S. Gibson

Received: 18 May 2021

Accepted: 11 June 2021

Published: 16 June 2021

Publisher's Note: MDPI stays neutral with regard to jurisdictional claims in published maps and institutional affiliations.

Copyright: (c) 2021 by the authors. Licensee MDPI, Basel, Switzerland. This article is an open access article distributed under the terms and conditions of the Creative Commons Attribution (CC BY) license (https:/ / creativecommons.org/licenses/by/ $4.0 /)$.

\begin{abstract}
MICA (major histocompatibility complex class I chain-related gene A) interacts with NKG2D on immune cells to regulate host immune responses. We aimed to determine whether MICA alleles are associated with AS susceptibility in Taiwanese. MICA alleles were determined through haplotype analyses of major MICA coding SNP (cSNP) data from 895 AS patients and 896 normal healthy controls in Taiwan. The distributions of MICA alleles were compared between AS patients and normal healthy controls and among AS patients, stratified by clinical characteristics. ELISA was used to determine soluble MICA (sMICA) levels in serum of AS patients and healthy controls. Stable cell lines expressing four major MICA alleles $\left(M I C A^{*} 002, M I C A^{*} 008, M I C A^{*} 010\right.$ and $\left.M I C A^{*} 019\right)$ in Taiwanese were used for biological analyses. We found that $M I C A^{*} 019$ is the only major MICA allele significantly associated with AS susceptibility $\left(\mathrm{P}_{F D R}=2.25 \times 10^{-115}\right.$; OR, 14.90; 95\% CI, 11.83-18.77) in Taiwanese. In addition, the $M I C A^{*} 019$ allele is associated with syndesmophyte formation $\left(\mathrm{P}_{F D R}=0.0017\right.$; OR, 1.69; 95\% CI, 1.29-2.22) and HLA-B27 positivity $\left(\mathrm{P}_{F D R}=1.45 \times 10^{-33}\right.$; OR, 28.79; 95\% CI, 16.83-49.26) in AS patients. Serum sMICA levels were significantly increased in AS patients as compared to healthy controls. Additionally, MICA*019 homozygous subjects produced the highest levels of sMICA, compared to donors with other genotypes. Furthermore, in vitro experiments revealed that cells expressing $M I C A^{*} 019$ produced the highest level of sMICA, as compared to other major MICA alleles. In summary, the $M I C A^{*} 019$ allele, producing the highest levels of sMICA, is a significant risk factor for AS and syndesmophyte formation in Taiwanese. Our data indicate that a high level of sMICA is a biomarker for AS.
\end{abstract}

Keywords: MICA; AS; soluble MICA; HLA-B27; syndesmophyte

\section{Introduction}

Ankylosing spondylitis (AS), a form of insidious and debilitating spondyloarthritis (SpA), is characterized by chronic inflammation and osteo-proliferation of the axial skeletons, including the spine and sacroiliac joints, usually resulting in bone fusion of affected areas [1]. Cells of innate and adaptive immune systems participate in the initiation, development and perpetuation of AS. However, the most relevant immune cell type in the pathogenesis of AS has not been fully elucidated [2]. Natural killer (NK) 
cells, particularly the CD56 $6^{\text {bright }}$ subset of NK cells with immune-regulatory properties, accumulate in inflammatory tissue sites (such as synovial membrane and skin lesions) of rheumatoid arthritis and psoriatic patients [3-6]. AS patients have increased frequencies of $\mathrm{CD}^{2} 6^{+} \mathrm{CD} 16^{+}$and $\mathrm{CD} 56^{\mathrm{dim}} \mathrm{CD} 16^{+} \mathrm{NK}$ cells, indicating a role of $\mathrm{NK}$ cells or subsets of NK cells in AS pathogenesis [7-9].

NK cells, a type of lymphocytes of the innate immune system, serve as regulatory immune cells in shaping adaptive immune responses by interacting with dendritic cells, macrophages, T cells and endothelial cells. NK cells represent the founding family member of the innate lymphoid cells (ILCs), which functionally inhibit or exacerbate immune responses based on signals from inhibitory and activating receptors [10,11]. Accumulating evidence points to the concept that NK cells are effector cells that can either contribute to or protect against inflammation and autoimmunity [12-16]. NK cells play a protective role in the development of experimental arthritis, an effect possibly mediated by suppressing Th17 cell generation via IFN- $\gamma$ production [17].

The breakdown of the delicate balance between immune activation and tolerance leads to autoimmune responses. The major histocompatibility complex class I chainrelated gene A (MICA) regulates immune responses through interaction with NKG2D (receptor natural killer group 2, member D), which mediates activation or co-stimulation of NK cells and subsets of T cells [18-20]. MICA, a member of non-classical MHC class I family, is highly polymorphic, reminiscent of the classical MHC class I genes. Numerous MICA alleles exist in human populations. Previous genetic and functional analyses of MICA variants shed some light into mechanistic roles of MICA in immune responses and inflammation [21-24]. MICA coding SNP (cSNPs) and alleles were associated with AS susceptibility in American Caucasians and Han Chinese populations [25]. Additionally, MICA promoter SNP rs4349859, that was previously used as the HLA-B27-tag SNP, had the strongest association with AS in Europeans [26]. However, the MICA allele profiles vary significantly in different ethnic populations. Different genetic backgrounds and environmental factors may also influence the effect of MICA alleles on the pathogenesis of inflammatory diseases. Therefore, MICA allele or alleles may affect AS susceptibility in a population-specific fashion. Additionally, phenotype-genotype analyses of populationspecific MICA alleles may provide insights into the mechanistic role of MICA alleles in the pathogeneses of AS. In the current study, we established a comprehensive profile of MICA alleles in Taiwanese by sequence analyses of a large number of human subjects. Most importantly, we identified the MICA*019 allele as a major risk factor for AS in Taiwanese. Ex vivo experiments revealed that genotypes containing the $M I C A^{*} 019$ allele are significantly associated with serum soluble MICA (sMICA) levels. Our data suggest a unique role for

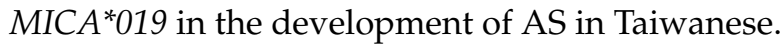

\section{Materials and Methods}

\subsection{Study Subjects}

A total of 895 AS patients ( 725 males and 170 females), who fulfilled the 1984 revised New York diagnostic criteria for AS [27], were recruited at the Chang Gung Memorial Hospital in Taiwan. Two rheumatologists independently evaluated lateral syndesmophyte formation and graded the severity of AS, according to the modified Stoke Ankylosing Spondylitis Spinal Score (mSASSS), after a 10-year observation [28]. Based on radiography, patients were separated into group 1 (no syndesmophytes), group 2 (fewer than 4 syndesmophytes, mSASSS $<24$ ), or group 3 ( 4 or more syndesmophytes, mSASSS $\geq 24$ ), as previously described [29]. Detailed demographical information of the study subjects is listed in Supplementary Table S1. A total of 896 healthy blood donors (752 males and 144 females) were recruited as normal healthy controls. One husband and twelve AS patients were tested for sMICA levels who received NSAID and DMARDs (sulfasalazine mostly) but not biologic agents. All experimental protocols were approved by the ethics committee of Chang Gung Memorial Hospital with IRB protocol\# 104-9983B and informed consents were obtained from all subjects. 


\subsection{DNA Sequence Analysis of MICA}

The MICA-specific genomic DNA fragment containing exons 2, 3, 4 and 5 amplified by PCR was used for DNA sequence analysis of MICA. The IMGT/HLA database (http: //ftp.ebi.ac.uk/pub/databases/ipd/imgt/hla/fasta/MICA_nuc.fasta, release date: 2020 (accessed on 1 January 2021)) was used to assign 105 MICA haplotypes or alleles.

\subsection{Determination of Soluble MICA (sMICA) Levels in Serum Samples}

Serum samples of normal healthy controls and AS patients were used in the ELISA analysis of sMICA. Serum sMICA levels were determined in triplicates using a sandwich MICA DuoSet ELISA kit (R\&D Systems, Minneapolis, MN, USA), according to the manufacturer's instructions.

\subsection{Generation of Human MICA Expression Constructs}

MICA cDNAs of peripheral blood mixed mononuclear cells from the carriers of MICA alleles $\left(M I C A^{*} 002, M I C A^{*} 008, M I C A^{*} 010\right.$ and $\left.M I C A^{*} 019\right)$ were amplified by RT-PCR and were subsequently cloned into the lentiviral vector pCDH-CMV-EF1-copGFP (Systems Biosciences, Palo Alto, CA, USA).

\subsection{Generation of Cell Lines Expressing MICA Alleles}

The C1R (ATCC\#CRL-1573, Manassas, VA, USA) and LCL-721.221 (ATCC\#CRL-1855) stable cell lines expressing empty vector $M I C A^{*} 002, M I C A^{*} 008, M I C A^{*} 010$, or $M I C A^{*} 019$ alleles were established for analyses of sMICA, exosomal MICA and cellular MICA. Membrane-bound MICA was analyzed by the flow cytometry analysis.

\subsection{Western Blot Analyses and Detection of sMICA, Exosomal MICA and Cellular MICA}

The ultracentrifugation supernatant fractions of cell culture medium containing sMICA were immunoprecipitated with anti-human MICA/MICA (Biolegend, San Diego, CA, USA) and protein G Mag sepharose Xtra beads (GE Healthcare, Chicago, IL, USA). The immunoprecipitation-concentrated sMICA, the isolated exosomes and total cell lysate were used for western blot analyses to determine amounts of sMICA, exosomal MICA and cellular MICA.

\subsection{Statistical Analysis}

Single-locus analyses of MICA cSNPs were performed to compare distributions of genotypes and alleles between normal healthy controls and AS patients. Linkage disequilibrium (LD) between marker loci or cSNPs was measured and haplotype blocks were constructed using Haploview 4.2 (Broad Institute, Cambridge, MA, USA; http: //www.broad.mit.edu/mpg/haploview (accessed on 1 October 2020)). Associations of the estimated haplotypes or alleles and disease status were tested in logistic regression models. The 5\% level of significance for $p$-values was used for all the analyses.

\subsection{Supplementary Methods}

Detailed materials and methods are described in the Supplementary Methods section of the Online Supplementary Information.

\section{Results}

\subsection{MICA cSNP and Alleles in Taiwanese}

The spectra of MICA cSNPs and alleles were determined by sequencing analysis of 896 Taiwanese healthy blood donors (normal healthy controls) and 895 AS patients. Among 32 total MICA cSNPs, that were identified in the combined population of healthy controls and AS patients, 22 are common cSNPs within MICA extracellular domains (seven in exon 2: rs9380254, rs1063630, rs1063631, rs1051785, rs17200158, rs1051786 and rs1063632; eight in exon 3: rs1051790, rs41539919, rs1051792, rs576467210, rs3819268, rs1051794, rs1131896 and rs1131897; seven in exon 4: rs17206680, rs1051796, rs1051797, rs1051798, rs1140700, 
rs1051799 and rs1063635). Sixteen common cSNPs (four in the exon 2, seven in the exon 3 and five in the exon 4) are non-synonymous cSNPs that lead to changes of amino acid codons in the MICA extracellular domains (Supplementary Table S2). In the combined population of normal controls and AS patients, the total number of $M I C A$ alleles was estimated to be $>100$, among which nine $M I C A$ alleles $\left(M I C A^{*} 019, M I C A^{*} 008, M I C A^{*} 010\right.$, $M I C A^{*} 002, M I C A^{*} 004, M I C A^{*} 012, M I C A^{*} 045, M I C A^{*} 033$ and $\left.M I C A^{*} 007\right)$ have the allele frequencies of $>0.01$ (Table 1 ). The linkage disequilibrium (LD) analysis confirmed that several MICA allele-tag SNPs are in strong LD $\left(\mathrm{r}^{2}>0.9\right)$ with specific MICA alleles in Taiwanese (Supplementary Table S3).

Table 1. Comparison of MICA allele frequencies between Taiwanese normal healthy controls and AS patients.

\begin{tabular}{|c|c|c|c|c|c|c|c|}
\hline \multirow{2}{*}{ MICA Allele } & \multicolumn{3}{|c|}{ Estimated Frequency Trend Test } & \multicolumn{2}{|c|}{ Logistic Regression } & \multicolumn{2}{|c|}{$\begin{array}{l}\text { Logistic Regression } \\
\text { Adjusted for Sex }\end{array}$} \\
\hline & $\operatorname{AS}(2 N=1790)$ & Control $(2 \mathrm{~N}=1792)$ & $p$ Value & $P_{F D R}$ Value & OR $(95 \%$ CI) & $P_{F D R}$ Value & OR $(95 \%$ CI $)$ \\
\hline MICA*019:01 & $765(42.74 \%)$ & $157(8.76 \%)$ & $<0.00001$ & $1.91 \times 10^{-115}$ & $\begin{array}{c}14.86 \\
(11.80-18.71)\end{array}$ & $2.25 \times 10^{-115}$ & $\begin{array}{c}14.90 \\
(11.83-18.77)\end{array}$ \\
\hline MICA*008:01:01 & $332(18.55 \%)$ & $510(28.46 \%)$ & $2.0 \times 10^{-12}$ & $1.4 \times 10^{-11}$ & $0.57(0.48-0.66)$ & $8.98 \times 10^{-12}$ & $0.56(0.48-0.66)$ \\
\hline $\mathrm{MICA}^{* 010: 01}$ & $192(10.73 \%)$ & $287(16.02 \%)$ & $1.86 \times 10^{-6}$ & $4.77 \times 10^{-6}$ & $0.62(0.50-0.75)$ & $4.50 \times 10^{-6}$ & $0.61(0.50-0.75)$ \\
\hline $\mathrm{MICA}^{* 002: 01}$ & $190(10.61 \%)$ & $376(20.98 \%)$ & $3.82 \times 10^{-17}$ & $8.05 \times 10^{-16}$ & $0.45(0.37-0.54)$ & $7.33 \times 10^{-16}$ & $0.44(0.37-0.54)$ \\
\hline MICA*004 & $73(4.08 \%)$ & $134(7.48 \%)$ & $1.70 \times 10^{-5}$ & $4.06 \times 10^{-5}$ & $0.53(0.40-0.71)$ & $4.98 \times 10^{-5}$ & $0.54(0.40-0.72)$ \\
\hline MICA*012:01 & $55(3.07 \%)$ & $144(8.04 \%)$ & $1.49 \times 10^{-10}$ & $1.92 \times 10^{-9}$ & $0.37(0.27-0.51)$ & $2.11 \times 10^{-9}$ & $0.37(0.27-0.51)$ \\
\hline MICA*045 & $51(2.85 \%)$ & $62(3.46 \%)$ & 0.343 & 0.334 & $0.82(0.57-1.19)$ & 0.360 & $0.83(0.57-1.20)$ \\
\hline $\mathrm{MICA}^{* 033}$ & $39(2.18 \%)$ & $2(0.11 \%)$ & $1.17 \times 10^{-8}$ & $6.46 \times 10^{-5}$ & $\begin{array}{c}19.36 \\
(4.66-80.37)\end{array}$ & $6.71 \times 10^{-5}$ & $\begin{array}{c}19.23 \\
(4.63-79.86)\end{array}$ \\
\hline $\mathrm{MICA}^{* 007: 01}$ & $26(1.45 \%)$ & $19(1.06 \%)$ & 0.291 & 0.336 & $1.38(0.76-2.51)$ & 0.360 & $1.38(0.76-2.51)$ \\
\hline $\mathrm{MICA}^{* 018: 01}$ & $5(0.28 \%)$ & $4(0.22 \%)$ & 0.738 & 0.738 & $1.25(0.34-4.68)$ & 0.784 & $1.20(0.32-4.51)$ \\
\hline others & $62(3.46 \%)$ & $97(5.41 \%)$ & & & & & \\
\hline
\end{tabular}

\subsection{Association of MICA cSNPs with AS Susceptibility in Taiwanese}

Single-locus analyses revealed that most of MICA cSNPs were significantly associated with AS susceptibility and $H L A-B 27$ positivity in AS patients (Supplementary Tables S4 and S5).

\subsection{Association of MICA Alleles with AS Susceptibility in Taiwanese}

In normal healthy controls, only seven MICA alleles $\left(M I C A^{*} 019, M I C A^{*} 008, M I C A^{*} 010\right.$, $M I C A^{*} 002, M I C A^{*} 004, M I C A^{*} 012$ and $M I C A^{*} 045$ ) had allele frequencies of $>0.03$ (or $>3 \%$ ). We assigned those seven MICA alleles as Taiwanese-specific major alleles, which account for about $93 \%$ of total MICA alleles identified in Taiwanese normal healthy population (Table 1). As shown in Table $1, M I C A^{*} 019$ is the only main allele that was significantly associated with a risk for AS susceptibility $\left(\mathrm{P}_{F D R}=2.25 \times 10^{-115}\right.$; OR, 14.90; 95\% CI, 11.83-18.77). On the other hand, five main MICA alleles $\left(M I C A{ }^{*} 008, M I C A{ }^{*} 010, M I C A\right.$ ${ }^{*} 002, M I C A{ }^{*} 004$ and $M I C A{ }^{*} 012$ ) were significantly associated with protection against AS $\left(M I C A^{*} 008: \mathrm{P}_{F D R}=8.98 \times 10^{-12} ; \mathrm{OR}, 0.56 ; 95 \%\right.$ CI, 0.48-0.66. MICA*010: $\mathrm{P}_{F D R}=4.5 \times 10^{-6}$; OR, 0.61; 95\% CI, 0.50-0.75. MICA*002: $\mathrm{P}_{F D R}=7.33 \times 10^{-16} ; \mathrm{OR}, 0.44 ; 95 \%$ CI, 0.37-0.54. MICA*004: $\mathrm{P}_{F D R}=4.98 \times 10^{-5} ; \mathrm{OR}, 0.5495 \%$ CI, 0.40-0.72. MICA*012: $\mathrm{P}_{F D R}=2.11 \times 10^{-9}$; OR, $0.37 ; 95 \%$ CI, 0.27-0.51).

\subsection{Associations of MICA Alleles with Syndesmophyte Formation in AS Patients}

Syndesmophytes reflect main features of spinal structural damage of AS, due to inflammation and ossification of the outer fibers of the annulus fibrosus. Among seven main MICA alleles, MICA*019 was significantly associated with the risk for syndesmophyte formation $\left(\mathrm{P}_{F D R}=0.0017\right.$; OR, 1.69; 95\% CI, 1.29-2.22) among AS patients (Table 2). 
Table 2. Comparison of MICA allele frequencies between AS patients positive for syndesmophyte formation $\left(\right.$ Synd $\left.^{+}\right)$and AS patients negative for syndesmophyte formation $\left(\right.$ Synd $\left.^{-}\right)$.

\begin{tabular}{|c|c|c|c|c|c|c|c|}
\hline \multirow{2}{*}{ MICA Allele } & \multicolumn{3}{|c|}{ Estimated Frequency Trend Test } & \multicolumn{2}{|c|}{ Logistic Regression } & \multicolumn{2}{|c|}{$\begin{array}{l}\text { Logistic Regression } \\
\text { Adjusted for Sex }\end{array}$} \\
\hline & $\begin{array}{c}\text { Synd }^{+} \\
(2 \mathrm{~N}=732)\end{array}$ & $\begin{array}{c}\text { Synd }^{-} \\
(2 \mathrm{~N}=1058)\end{array}$ & $p$ Value & $\mathbf{P}_{\text {FDR }}$ Value & OR (95\% CI) & $\mathbf{P}_{\text {FDR Value }}$ & OR $(95 \%$ CI) \\
\hline $\mathrm{MICA}^{* 019: 01}$ & $343(46.86 \%)$ & $422(39.89 \%)$ & $8.72 \times 10^{-5}$ & 0.001 & $1.68(1.29-2.19)$ & 0.0017 & $1.69(1.29-2.22)$ \\
\hline MICA*008:01:01 & $119(16.26 \%)$ & $213(20.13 \%)$ & 0.030 & 0.077 & $0.75(0.57-0.97)$ & 0.120 & $0.77(0.59-1.01)$ \\
\hline MICA*010:01 & $65(8.88 \%)$ & $127(12.00 \%)$ & 0.029 & 0.077 & $0.70(0.50-0.97)$ & 0.120 & $0.71(0.51-1.00)$ \\
\hline $\mathrm{MICA}^{* 002: 01}$ & $72(9.84 \%)$ & $118(11.15 \%)$ & 0.352 & 0.401 & $0.86(0.63-1.19)$ & 0.518 & $0.87(0.63-1.21)$ \\
\hline MICA*004 & $40(5.46 \%)$ & $33(3.12 \%)$ & 0.0196 & 0.071 & $1.81(1.13-2.92)$ & 0.081 & $1.84(1.12-3.02)$ \\
\hline MICA*012:01 & $26(3.55 \%)$ & $29(2.74 \%)$ & 0.397 & 0.401 & $1.32(0.76-2.28)$ & 0.518 & $1.27(0.72-2.22)$ \\
\hline MICA*045 & $14(1.91 \%)$ & $37(3.50 \%)$ & 0.063 & 0.105 & $0.54(0.29-1.01)$ & 0.120 & $0.53(0.28-1.00)$ \\
\hline MICA*033 & $16(2.19 \%)$ & $23(2.17 \%)$ & 1 & 0.987 & $1.01(0.53-1.90)$ & 0.841 & $1.07(0.55-2.07)$ \\
\hline $\mathrm{MICA}^{* 007: 01}$ & $7(0.96 \%)$ & $19(1.80 \%)$ & 0.199 & 0.247 & $0.52(0.22-1.26)$ & 0.191 & $0.49(0.20-1.19)$ \\
\hline $\mathrm{MICA}^{* 018: 01}$ & $1(0.14 \%)$ & $4(0.38 \%)$ & 0.641 & 0.401 & $0.36(0.04-3.23)$ & 0.540 & $0.45(0.05-4.31)$ \\
\hline others & $29(3.96 \%)$ & $33(3.12 \%)$ & & & & & \\
\hline
\end{tabular}

\subsection{Associations of MICA Alleles with HLA-B27 Positivity in AS Patients}

$H L A-B 27$ is a recognized genetic risk factor for AS. In the current study, we found that $M I C A^{*} 019$ was also significantly associated with $H L A-B 27$ positivity $\left(\mathrm{P}_{F D R}=1.45 \times 10^{-33}\right.$; OR, 28.79; 95\% CI, 16.83-49.26) in AS patients (Table 3). On the other hand, five out of seven main MICA alleles were negatively associated with $H L A-B 27$ positivity in AS patients. Our data suggest that $M I C A^{*} 019$ allele may genetically interact with $H L A-B 27$ to contribute to the development of AS. To control the effect of linkage disequilibrium between MICA alleles and HLA-B27 on AS, we carried out an MICA genetic analysis of AS patients and healthy controls stratified by the presence and absence of $H L A-B 27$. As shown in Supplementary Table S6, MICA*019 resulted to significantly associate with AS susceptibility $\left(\mathrm{P}_{F D R}=0.012\right.$; OR, $2.84 ; 95 \% \mathrm{CI}, 1.51-5.33$; power: 0.581$)$ in analyzing $H L A-B 27$ positive AS patients and $H L A-B 27$ positive healthy controls, indicating that the $M I C A^{*} 019$ allele is an additional AS risk factor besides HLA-B27. Nevertheless, MICA*019 was not significantly associated with AS susceptibility among subjects negative for HLA$B 27$ ( $p=0.925$; OR, 1.11; 95\% CI, 0.67-1.86; power: 0.083) (Supplementary Table S7). Fitted logistic regression models controlling for sex and age were used to test the interactions of HLA-B27 and MICA alleles (one at a time). We found that the interaction between HLA-B27 and MICA ${ }^{*} 019$ had a significant effect on AS $(p=0.0241)$, while all other interactions were not significant $(p>0.05)$. Taken together, our data suggest that MICA*019 and HLA-B27 may play synergistic roles in the pathogenesis of AS.

Table 3. Comparison of MICA allele frequencies between HLA-B27 ${ }^{+}$and HLA-B27 ${ }^{-}$AS patients.

\begin{tabular}{|c|c|c|c|c|c|c|c|}
\hline \multirow{2}{*}{ MICA Allele } & \multicolumn{3}{|c|}{ Estimated Frequency Trend Test } & \multicolumn{2}{|c|}{ Logistic Regression } & \multicolumn{2}{|c|}{$\begin{array}{l}\text { Logistic Regression } \\
\text { Adjusted for Sex }\end{array}$} \\
\hline & $\begin{array}{c}\mathrm{B} 27^{+} \\
(2 \mathrm{~N}=1568)\end{array}$ & $\begin{array}{c}\mathrm{B}^{2} 7^{-} \\
(2 \mathrm{~N}=222)\end{array}$ & $p$ Value & $\mathbf{P}_{\text {FDR Value }}$ & OR (95\% CI) & $P_{\text {FDR Value }}$ & OR $(95 \%$ CI) \\
\hline $\mathrm{MICA}^{* 019: 01}$ & $746(47.58 \%)$ & $19(8.56 \%)$ & $2.99 \times 10^{-50}$ & $6.71 \times 10^{-34}$ & $\begin{array}{c}28.49 \\
(16.72-48.53)\end{array}$ & $1.45 \times 10^{-33}$ & $\begin{array}{c}28.79 \\
(16.83-49.26)\end{array}$ \\
\hline MICA*008:01:01 & $274(17.47 \%)$ & $58(26.13 \%)$ & 0.001 & 0.002 & $0.55(0.39-0.79)$ & 0.004 & $0.57(0.40-0.81)$ \\
\hline MICA*010:01 & $148(9.44 \%)$ & $44(19.82 \%)$ & $1.01 \times 10^{-6}$ & $1.02 \times 10^{-5}$ & $0.39(0.26-0.58)$ & $1.78 \times 10^{-5}$ & $0.39(0.26-0.59)$ \\
\hline $\mathrm{MICA}^{* 002: 01}$ & $138(8.80 \%)$ & $52(23.42 \%)$ & $5.47 \times 10^{-12}$ & $7.18 \times 10^{-10}$ & $0.27(0.18-0.41)$ & $9.17 \times 10^{-10}$ & $0.27(0.18-0.41)$ \\
\hline MICA*004 & $57(3.64 \%)$ & $16(7.21 \%)$ & 0.025 & 0.022 & $0.48(0.27-0.86)$ & 0.018 & $0.47(0.26-0.84)$ \\
\hline $\mathrm{MICA}^{*} 012: 01$ & $47(3.00 \%)$ & $8(3.60 \%)$ & 0.724 & 0.688 & $0.82(0.38-1.79)$ & 0.692 & $0.79(0.36-1.73)$ \\
\hline MICA*045 & $35(2.23 \%)$ & $16(7.21 \%)$ & 0.001 & 0.0003 & $0.29(0.16-0.55)$ & 0.0003 & $0.29(0.16-0.54)$ \\
\hline MICA*033 & $39(2.49 \%)$ & $0(0.00 \%)$ & 0.001 & 0.999 & (0.00-Inf) & 0.999 & $(0.00-\operatorname{Inf})$ \\
\hline $\mathrm{MICA}^{* 007: 01}$ & $24(1.53 \%)$ & $2(0.90 \%)$ & 0.720 & 0.665 & $1.72(0.40-7.38)$ & 0.692 & $1.68(0.39-7.25)$ \\
\hline $\mathrm{MICA}^{* 018: 01}$ & $4(0.26 \%)$ & $1(0.45 \%)$ & 0.964 & 0.688 & $0.56(0.06-5.09)$ & 0.792 & $0.66(0.07-6.09)$ \\
\hline other & $56(3.57 \%)$ & $6(2.70 \%)$ & & & & & \\
\hline
\end{tabular}




\subsection{Increased Levels of Serum sMICA in AS Patients and MICA*019 Homozygous AS Patients}

To examine the role of MICA in AS, we determined sMICA levels in AS patients and normal healthy controls. As shown in Figure 1A, we found that serum sMICA concentrations were significantly increased in AS patients $(\mathrm{N}=112$, sMICA concentration: $63.35 \pm 14.65 \mathrm{pg} / \mathrm{mL})$, as compared to normal healthy controls $(\mathrm{N}=92$, sMICA concentration: $6.224 \pm 5.417 \mathrm{pg} / \mathrm{mL})(p=0.001)$. Since $M I C A^{*} 019$ is the only main allele that was significantly associated with AS susceptibility, sMICA concentrations of AS patients who were either homozygous or heterozygous for $M I C A^{*} 019$ were used to analyze the effects of different MICA alleles on sMICA levels in the presence of $M I C A^{*} 019$. As shown in Figure $1 \mathrm{~B}, M I C A^{*} 019$ homozygous subjects $\left(M I C A^{*} 019 /{ }^{*} 019\right)$ produced significantly higher levels of sMICA than subjects with $M I C A^{*} 019 /{ }^{*} 010(p=0.0141)$ and $M I C A^{*} 019 /{ }^{*} 002$ ( $p=0.0051)$ genotypes. Although $M I C A^{*} 019$ homozygous subjects $\left(M I C A^{*} 019 /{ }^{*} 019\right)$ produced higher levels of sMICA than MICA*019/*008 heterozygous subjects, the difference did not reach statistical significance. Our data indicate that $M I C A^{*} 019$ significantly affects sMICA production. Notably, no single SNP was found to associate with sMICA levels and serum sMICA concentrations were not correlated with ESR, CRP, BASFI (Bath Ankylosing Spondylitis Functional Index) and BASDAI (Bath Ankylosing Spondylitis Disease Activity Index) (data not shown).

A.

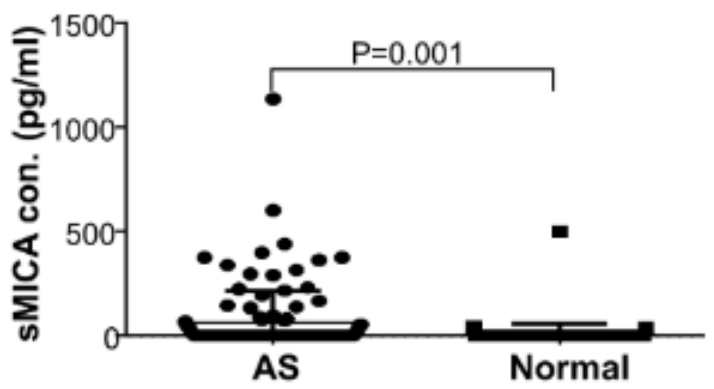

B.

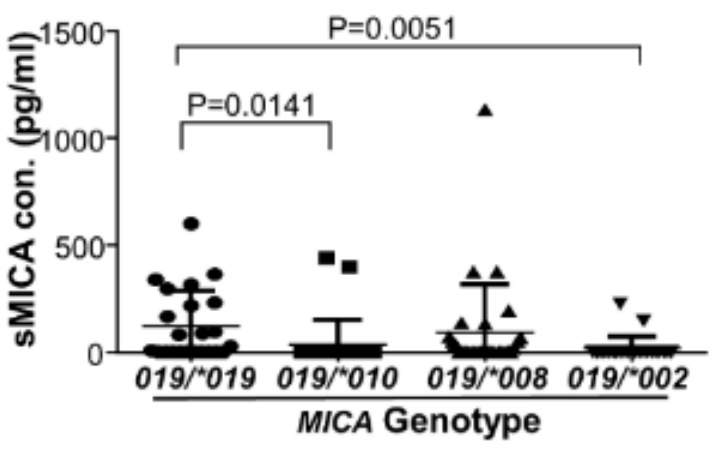

Figure 1. Elevated levels of soluble MICA (sMICA) in AS patients and MICA*019 homozygous genotype subjects. (A) Serum sMICA levels in AS patients and normal healthy controls. The serum sMICA levels were significantly increased in AS patients $(\mathrm{N}=112$, sMICA concentration: $63.35 \pm 14.65 \mathrm{pg} / \mathrm{mL})$, as compared to normal healthy controls $(\mathrm{N}=92$, sMICA concentration: $6.224 \pm 5.417 \mathrm{pg} / \mathrm{mL})(p=0.001)$. (B) Serum sMICA levels in AS patients carrying MICA*019 allele. $M I C A^{*} 019 / * 019$ subjects produced significantly more sMICA $(\mathrm{N}=23$, sMICA concentration: $122.8 \pm 34.39 \mathrm{pg} / \mathrm{mL})$ than $M I C A^{*} 019 /{ }^{*} 010(\mathrm{~N}=30$, sMICA concentration: $27.88 \pm 19.40)(p=0.0141)$ and $M I C A^{*} 019 /{ }^{*} 002(\mathrm{~N}=23$, sMICA concentration: $16.10 \pm 11.39)(p=0.0051)$ subjects. $M I C A^{*} 019 /{ }^{*} 019$ subjects produced higher levels of sMICA ( $\mathrm{N}=23$, sMICA concentration: $122.8 \pm 34.39 \mathrm{pg} / \mathrm{mL})$ than MICA* $019 / * 008$ subjects $(\mathrm{N}=29$, sMICA concentration: $90.95 \pm 41.76 \mathrm{pg} / \mathrm{mL}$ ), but the difference was statistically insignificant. 


\subsection{Cells Expressing MICA*019 Allele Produces the Highest Amount of sMICA In Vitro}

$M I C A^{*} 019$ is significantly associated with susceptibility to AS disease, while $M I C A^{*} 002$, $M I C A^{*} 008$ and $M I C A^{*} 010$ are protective against AS development (Table 1). In addition, $M I C A^{*} 019$ homozygosity is associated with increased sMICA concentrations, whereas the presence of the $M I C A^{*} 002, M I C A^{*} 008$ and $M I C A^{*} 010$ alleles is associated with lower levels of sMICA in AS patients (Figure 1B). To confirm the effect of MICA*019 on sMICA production, we carried out in vitro experiments using C1R and LCL-721.221 cell lines stably expressing $M I C A^{*} 019, M I C A^{*} 002, M I C A^{*} 008$, or $M I C A^{*} 010$ alleles. As shown in Figure $2 \mathrm{~A}$ (right column of panels), MICA*019 cells expressed the highest level of surface MICA (geometric mean: 905), as compared to $M I C A^{*} 002$ (geometric mean: 303) and MICA*008 (geometric mean: 627) cells. However, $M I C A^{*} 010$ cells failed to express surface MICA on cell membrane, which is consistent with previous findings by Li et al. [30]. The immunoblot analysis revealed that $C 1 \mathrm{R}$ cells expressing $M I C A^{*} 019$ cells (Lane 6) produced the highest amount of sMICA in culture supernatants among cells expressing four MICA alleles $\left(M_{I C}{ }^{*} 002, M I C A^{*} 008, M I C A^{*} 010\right.$ and $\left.M I C A^{*} 019\right)$ (Figure 2B). MICA*008 cells (Lane 4) produced more sMICA than MICA*002 cells (Lane 3), while $M I C A^{*} 010$ cells (Lane 5) produced little if any sMICA in western blot analyses. Similar results were obtained with LCL-721.221 cells stably expressing $M I C A^{*} 002, M I C A^{*} 008, M I C A^{*} 010$ and $M I C A^{*} 019$ alleles (Figure 2C). We also carried out ELISA to determine sMICA levels in the culture supernatants of the LCL-721.221 cells stably expressing $M I C A^{*} 002, M I C A^{*} 008, M I C A^{*} 010$ or $M I C A^{*} 019$. Again, the $M I C A^{*} 019$ cell culture supernatant contained the highest level of sMICA, which was followed by the $M I C A^{*} 008$ cell culture supernatant (Figure 2D). Surprisingly, sMICA concentrations were so low in the MICA*002 and $M I C A^{*} 010$ cell culture supernatants that sMICA were undetectable by ELISA (Figure 2D). Our data confirmed that the MICA*019 allele is the highest sMICA producer, while $M I C A^{*} 008$ also produces significantly more sMICA than MICA*002 and MICA*010, suggesting a biological mechanism by which homozygous $M I C A^{*} 019 / 019$ subjects produced the highest levels of sMICA among subjects carrying at least one $M I C A^{*} 019$ allele (Figure 1B). Interestingly, we found that $M I C A^{*} 008$ cells (Lane 4) produced the highest amount of exosomal MICA among four MICA alleles (Figure $3 \mathrm{~A}, \mathrm{~B}$ ). Although the MICA protein could be detected in MICA*010 cell lysates (Lane 5, right panels of Figure $3 \mathrm{~A}, \mathrm{~B}$ ) in both C1R and LCL cells, MICA*010 cells failed to expressed cell surface MICA (Figure 2A). In addition, $M I C A^{*} 010$ was unable to produce detectable amounts of sMICA (Figure 2B-D) and exosomal MICA production (Lane 5, left panels of Figure $3 \mathrm{~A}, \mathrm{~B})$, suggesting the $M I C A^{*} 10$ protein is intracellularly trapped and is unable to express as surface MICA and sMICA. 
A.

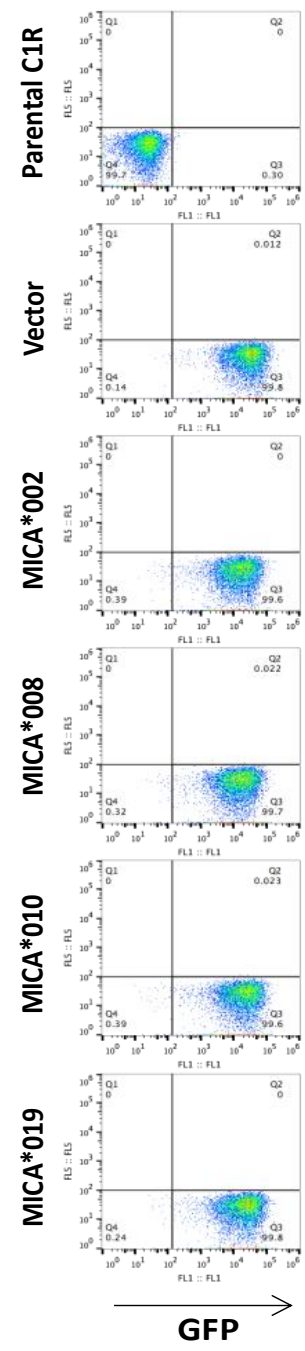

B.
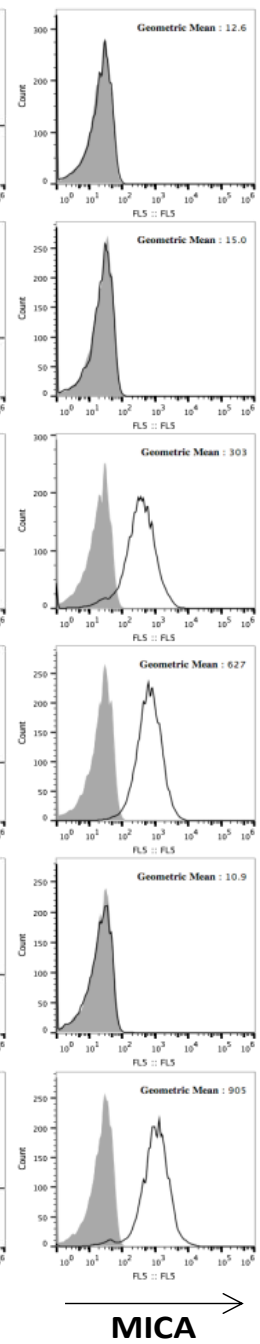

D.

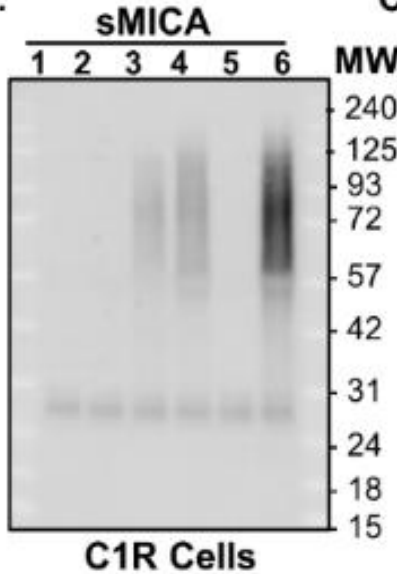

C.
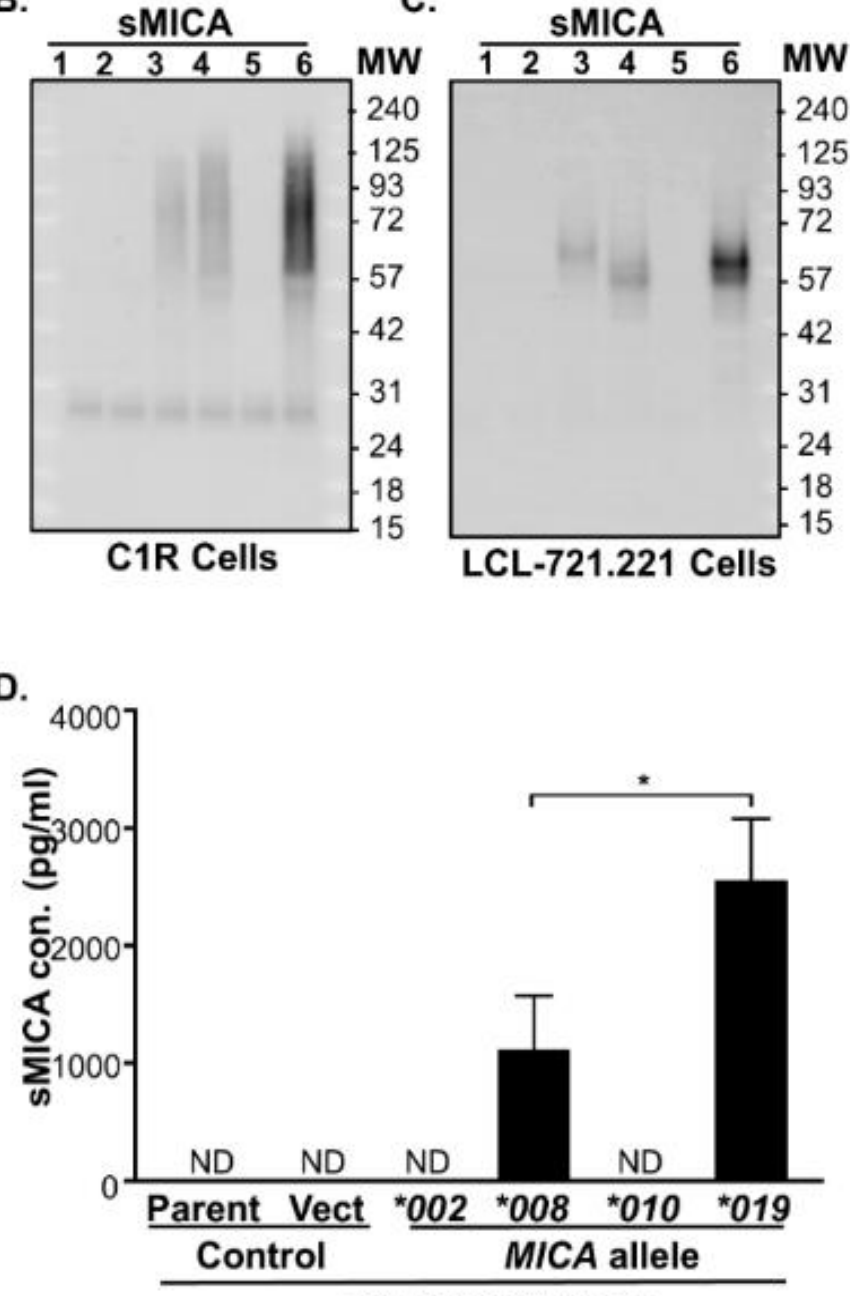

Figure 2. Surface expressions and soluble MICA (sMICA) productions of MICA alleles. (A) Representatives of transduced cells expressing vector and MICA alleles $\left(M I C A^{*} 002, M I C A^{*} 008, M I C A^{*} 010\right.$ and $\left.M I C A^{*} 019\right)$ were sorted for equivalent GFP expressions (left panels). The MICA*019 cells expressed the highest level of surface MICA (geometric mean: 905 ), as compared to MICA*002 (geometric mean: 303) and MICA*008 (geometric mean: 627) cells, while MICA*010 cells failed to express surface MICA on cell membrane. (B) Western blot analysis of sMICA produced by C1R cells expressing MICA alleles. Ultracentrifugation was used to separate cell-free culture supernatants into supernatant fractions containing sMICA. Immunoprecipitation-concentrated sMICA were subjected to western blot analysis, as described in Materials and Methods. No sMICA could be detected from cell culture supernatants of parental C1R cells (Lane 1) and C1R cells expressing vector control (Lane 2). C1R cells expressing MICA*019 (Lane 6) produced the most sMICA in culture supernatants among cells expressing $M I C A^{*} 002$ (Lane 3), MICA*008 (Lane 4), MICA*010 (Lane 5) and $M I C A^{*} 019$. MICA*008 cells (Lane 4) produced more sMICA than $M I C A^{*} 002$ cells (Lane 3 ), while $M I C A^{*} 010$ cells (Lane 5) produced little if any sMICA. (C) Western blot analysis of culture supernatants from parental LCL-721.221 cells (Lane 1) and LCL-721.221cells stably expressing vector control (Lane 2), MICA*002 (Lane 3), MICA*008 (Lane 4), MICA*010 (Lane 5) and MICA*019 (Lane 6) alleles. Similar results were obtained as in C1R cells. (D) ELISA analysis of SMICA in the culture supernatants of the LCL-721.221 cells stably expressing MICA allele. The MICA*019 cell culture supernatant contained the highest level of sMICA, followed by the $M I C A^{*} 008$ cell culture supernatant. There were no detectable levels (ND) of sMICA in cell culture supernatants from parental LCL cells (parent), cells expressing empty vector (vector) and $M I C A^{*} 002$ and $M I C A^{*} 010$ alleles. All experiments were repeated at least three times and representative data are shown. 
A.

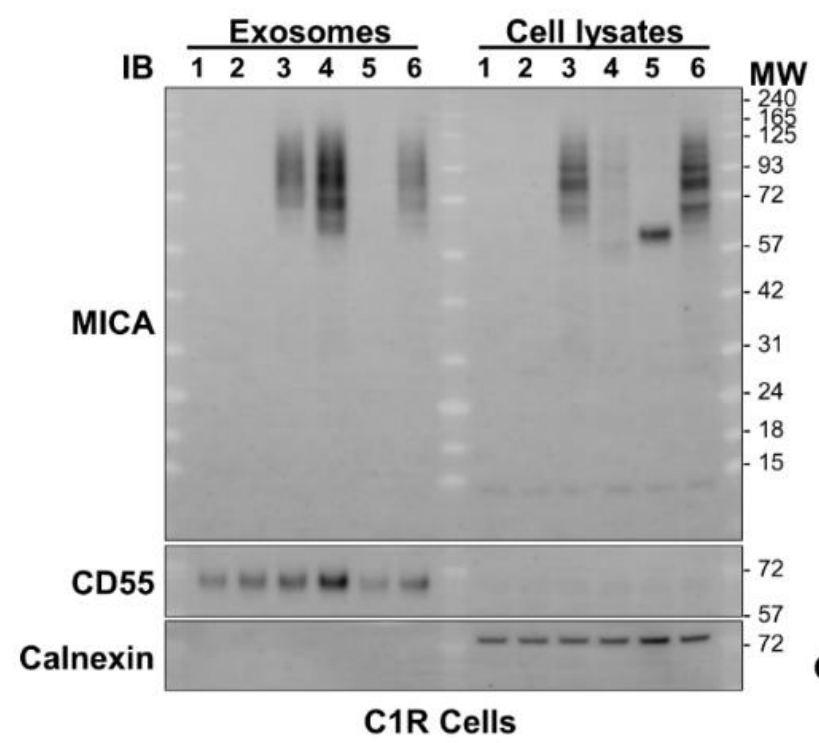

B.

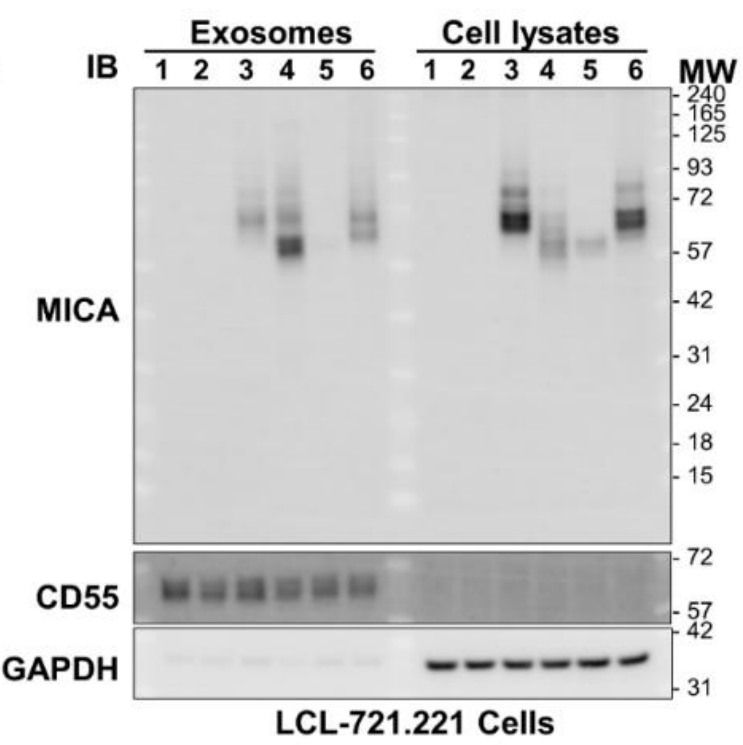

Figure 3. Western blot analyses of MICA from exosomes and cell lysates. (A) Ultracentrifugation of culture supernatants of C1R parental cells (Lane 1), C1R cells stably expressing empty vector (Lane 2), MICA*002 (Lane 3), MICA*008 (Lane 4), $M I C A^{*} 010$ (Lane 5) and $M I C A^{*} 019$ (Lane 6) was used to obtain exosomes in ultracentrifugation pellets. The parental C1R cells (Lane 1), C1R cells stably expressing empty vector (Lane 2), MICA*002 (Lane 3), MIC ${ }^{*} 008$ (Lane 4), MIC ${ }^{*} 010$ (Lane 5) and $M I C A^{*} 019$ (Lane 6) were lysed in lysis buffer to generate total cell lysates. Exosomes and total cell lysates were subjected to western blot analysis, as described in Materials and Methods. CD55 was used as a loading control to normalize the expression of MICA in exosomes and GAPDH as a loading control to normalize the expression of MICA in total cell lysates. C1R cells expressing $M I C A^{*} 008$ (Lane 4) produced the highest amount of exosomal MICA compared to cells expressing $M I C A^{*} 002$ (Lane 3) and $M I C A^{*} 019$ (Lane 6), while no exosomal MICA was produced from $M I C A^{*} 010$ (Lane 5) cells. Lysates of $M I C A^{*} 002$ (Lane 3) and MICA*019 (Lane 6) cells contained more intracellular MICA than MICA*008 (Lane 4) and $M I C A^{*} 010$ (Lane 5) cells. (B) Western blot analyses of exosomes and cell lysates from parental LCL-721.221 cells (Lane 1) and LCL-721.221cells stably expressing vector control (Lane 2), MICA*002 (Lane 3), MICA*008 (Lane 4), MICA*010 (Lane 5) and $M I C A^{*} 019$ (Lane 6) alleles. Similar results were obtained as in C1R cells. All experiments were repeated at least three times and representative data are shown.

\section{Discussion}

MHC gene composition (especially the positivity of $H L A-B 27)$ confers the greatest risk for AS, while non-MHC genes also contribute to the AS development process [31-33]. In this study, we have determined the comprehensive profile of MICA alleles in Taiwanese by analyzing a large number of subjects. We have obtained the most extensive MICA allele dataset that has ever been assembled for an Asian population. Most importantly, the $M I C A^{*} 019$ allele was identified as a major risk factor for AS in Taiwanese. Phenotypegenotype analyses revealed that $M I C A^{*} 019$ homozygosity was associated with the highest levels of sMICA production in Taiwanese AS patients. In vitro experiments confirmed that MICA*019 cells produced the larger amount of sMICA among main MICA alleles of Taiwanese. Our data suggest that MICA plays an important role in the development of AS, possibly through the increased production of sMICA.

MICA plays important roles in tumor surveillance and inflammation [22,34]. DNA damage, heat, viral infection and inflammation promote the expression of MICA, which triggers the activation of lymphocytes for immune responses. By engaging NKG2D and overriding the inhibitory signals of killer inhibitory receptors (KIRs) and/or CD94/NKG2A/B, MICA effectively activates NK, $\gamma \delta$ T cells and $\alpha \beta C D 8^{+} \mathrm{T}$ cells to kill virus-infected cells or tumor cells [34-36]. The MICA cSNP rs1051792G >A that causes amino acid substitution from valine to methionine at the position 129 (MICA-129Val>Met) significantly affects 
the interaction strength between MICA and NKG2D, the production of SMICA and the density of MICA on the plasma membrane [34,37-39]. The MICA-129Met variant has stronger binding affinity for NKG2D than MICA-129Val, leading to increased cytotoxicity and IFN- $\gamma$ release from NK cells and $\mathrm{CD}^{+} \mathrm{T}$ cells $[37,40]$. The interaction between high affinity the MICA-129Met variant and NKG2D could effectively downregulate NKG2D cell surface expression, impacting clinical outcomes of GVHD [38]. The MICA-129Val/Val homozygous genotype has been associated with higher levels of sMICA and the progression of multiple myeloma [40]. The microsatellite triplet repeat polymorphism within transmembrane segment also affect MICA functions [34]. However, functions of the MICA cSNP rs1051792G >A were mostly analyzed without considering the effect of other MICA cSNPs that may modify the functions of the SNP rs1051792G $>$ A. Multiple MICA alleles share the same SNP rs1051792G>A allele (e.g., both $M I C A^{*} 019$ and $M I C A^{*} 004$ contain the rs1051792G or 129Val allele; Supplementary Table S2), but have opposite effects on disease susceptibility $\left(M I C A^{*} 019\right.$ is a risk factor for AS, while $M I C A^{*} 004$ is protective against AS; Table 1). Therefore, the associations of MICA cSNP rs1051792G>A (or MICA-129Val $>$ Met) single locus with various disease susceptibilities need to be reassessed and MICA alleles (or MICA cSNP haplotypes) should be used to accurately evaluate the contribution of MICA to a specific disease in future association studies.

MICA alleles are associated with susceptibility to chronic autoimmune inflammatory diseases. The $M I C A^{*} 007$ allele was reportedly associated with AS and ulcerative colitis (UC), while $M I C A^{*} 019$ was associated with AS and Bechet's disease [25,41,42]. The associations of MICA variations with AS were examined in cohorts of European Americans and Han Chinese, leading to the identification of $M I C A^{*} 007$ as a significant risk allele for AS in both Caucasian and Han Chinese populations, independent of HLA-B27 (US cohort OR =60.66; Chinese cohort OR =7.78) [25]. However, a recent study with a large cohort of European ancestry (9429 AS cases and 13,459 controls) demonstrated no evidence of association between the MICA*007 allele and AS susceptibility. The lack of association between the $M I C A^{*} 007$ allele and AS risk was further confirmed in a relatively homogenous UK population (4198 AS cases, 9611 controls), which excluded the effect of population heterogeneity on the negative disease association between the MICA*007 allele and AS risk [43]. In the current study, we revealed a lack of association between $M I C A^{*} 007$ and AS susceptibility in Taiwanese. Therefore, it is questionable that the $M I C A^{*} 007$ allele is a common risk factor for AS in humans.

Besides $M I C A^{*} 007, M I C A^{*} 019$ was identified as another independent risk allele for AS in Han Chinese, while $M I C A^{*} 019$ was not associated with AS susceptibility in Americans with European ancestry, indicating that $M I C A^{*} 019$ may have a role in AS development in Han Chinese despite the proximity of MICA and HLA-B27 [25]. We found that MICA*019 is the only major risk allele for AS in Taiwanese and that $M I C A^{*} 019$ is also significantly associated with $H L A-B 27$ positivity in AS patients. $M I C A^{*} 019$ resulted to significantly associate with AS susceptibility in comparing $H L A-B 27$ positive AS patients with $H L A-B 27$ positive healthy controls, indicating that the $M I C A^{*} 019$ allele is an additional risk factor for AS. Moreover, MIC $A^{*} 019$ is significantly associated with syndesmophyte formation in AS patients, suggesting that MICA*019 is also a biomarker for AS severity. Male sex, elevated serum $C$-reactive protein levels and preexisting syndesmophytes are recognized as consistent clinical predictors, while genetic effects require further investigation [44]. Our data indicate that MICA may interact with HLA class I to modulate NK cell functions in Taiwanese. Taken together, our data suggest that the $M I C A^{*} 019$ may be a common major risk factor for AS susceptibility in Asians, albeit the exact mechanisms of MICA on bone remodeling in syndesmophyte formations remain to be elucidated.

Soluble MICA (sMICA) is generated by proteolytic shedding from the membranebound MICA of various cells. Levels of sMICA were significantly increased in rheumatoid arthritis (RA) patients, as compared to normal healthy controls, and RA patients with MICA-129Val/Val genotype had significantly higher sMICA levels than those with the MICA-129Met/Val or MICA-129Met/Met genotype [45]. More importantly, high levels of 
sMICA were significantly associated with severe deformed RA phenotype in south Indian Tamil population [46]. In this study, we found that AS patients produced significantly high levels of sMICA, as compared to healthy controls. In addition, AS patients with the homozygous MIC $A^{*} 019 / 019$ genotype produced the highest level of sMICA among AS patients. In vitro experiments confirmed that $M I C A^{*} 019$ cells produced the highest level of sMICA among cells expressing individual MICA alleles. Interestingly, MICA*008 cells produced lower levels of sMICA than $M I C A^{*} 019$ cells. However, MIC $A^{*} 008$ cells produced more sMICA than MIC $A^{*} 002$ cells and $M I C A^{*} 010$ cells, which may explain the observation that a high level of sMICA was produced in subjects carrying MICA$129 \mathrm{Val}$ [45], as both $\mathrm{MIC} A^{*} 019$ and $M I C A^{*} 008$ contain $129 \mathrm{Val}$, while $\mathrm{MIC} A^{*} 002$ has $129 \mathrm{Met}$ (Supplementary Table S2). Soluble MICA promote inflammation through the increased production of IFN- $\gamma$ by activated NK cells [45]. Therefore, it is reasonable to assume that the increased production of sMICA in AS and RA patients may exacerbate inflammatory responses and perpetuate inflammation in patients. Nevertheless, this study has limitations. First, this cross-sectional study cannot assess the longitudinal effect of sMICA on AS disease progression. Second, the exact mechanism for MICA to affect bone remodeling in syndesmophyte formations remains to be elucidated.

MIC $A^{*} 008$ is the most frequent MICA allele in Taiwanese (Table 1). MIC $A^{*} 008$ cells produced significantly more sMICA than $M I C A^{*} 002$ cells and $M I C A^{*} 010$ cells (Figure 2D). However, $M I C A^{*} 008$ is associated with protection against AS in Taiwanese, similarly to MIC $A^{*} 002$ and $M I C A^{*} 010$. MIC $A^{*} 008$ and $M I C A^{*} 019$ are almost identical in the extracellular domains, but very different in the C-terminal [25]. MIC $A^{*} 008$ contains an insertion of guanine at codon 295 (MICA A5.1) that results in a truncated MICA protein lacking part of the transmembrane domain and the entire cytoplasmic tail with a premature stop codon at position 304 [47]. MICA*008 is initially synthesized as a soluble protein, which is either secreted as sMICA by exocytosis, or processed with the attachment of GPI (glycosylphosphatidylinositol) for exosomal MICA production and for membrane surface expression [25]. We confirmed that $M I C A^{*} 008$ cells produced the highest amount of exosomal MICA among four MICA alleles (MICA*002, MIC $A^{*} 008, M I C A^{*} 010$ and $\left.M I C A^{*} 019\right)$ (Figure 3). Exosomes containing $\mathrm{MICA}^{*} 008$ downregulate NKG2D and inhibit functions of effectors cells $[48,49]$, which may be the mechanism underlying the association of $M I C A^{*} 008$ with the protection against AS.

Although the MICA protein could be detected in MIC $A^{*} 010$ cell lysates in both C1R and LCL cells, MIC $A^{*} 010$ cells did not produce detectable amounts of exosomal MICA and sMICA (Figure 2B-D) and failed to express on cell surface (Figure 2A). Our data demonstrate that the $M I C A^{*} 10$ protein is trapped intracellularly and is unable to express functional MICA, either in soluble form or in membrane-bound MICA, confirming that $M I C A^{*} 010$ is a non-functional MICA allele, as previously reported [30].

In summary, the MIC $A^{*} 019$ allele is a major risk factor for AS and disease severity in Taiwanese. AS patients produce significantly high levels of sMICA, which may have a role in the pathogenesis of AS.

Supplementary Materials: The following are available online at https:/ /www.mdpi.com/article/10 .3390/jpm11060564/s1, Table S1: Demographical information of Taiwanese AS patients and normal healthy controls, Table S2: MICA non-synonymous cSNPs and major alleles identified in Taiwanese normal healthy controls and AS patients, Table S3: The LD (r2) between cSNPs and MICA alleles in Taiwanese normal healthy controls and AS patients, Table S4: Association of MICA cSNP genotypes and alleles with AS susceptibility in Taiwanese, Table S5: Association of MICA cSNP genotypes and alleles with HLA-B27 positivity in AS patients, Table S6: Comparison of MICA alleles between AS patients and normal controls with HLA-B27 positive individuals, Table S7: Comparison of MICA alleles between AS patients and normal controls with HLA-B27 negative individua. Supplementary data accompanies this paper. 
Author Contributions: Conceptualization, resources, funding acquisition C.-M.W. and J.-Y.C. methodology, data curation, investigation K.-P.T. investigation Y.-J.J.W., J.-C.L. and J.-W.Z. supervision, A.L.Y. writing-original draft preparation J.-M.W. All authors have read and agreed to the published version of the manuscript.

Funding: This work was supported by funding from the Chang Gung Memorial Hospital (Grant numbers: CMRPG 5H0022, CMRPG 3J1422 and CMRPG 5I0061) and the Ministry of Science and Technology, Taiwan (Grant numbers: MOST 105-2314-B-182-068-MY3 and 107-2314-B-182-059-MY3). Dr. Wu's work was partially supported NIH grant (Grant numbers: R21AI149395).

Institutional Review Board Statement: The study was conducted according to the guidelines of the Declaration of Helsinki, and approved by the Institutional Review Board of Chang Gung Memorial Hospital (protocol code 201509983B0D001and approved on 15 February 2016).

Informed Consent Statement: Written informed consent has been obtained from the patients to publish this paper.

Data Availability Statement: Not applicable.

Acknowledgments: We greatly appreciate the Shin Chu Blood Donor Center for the collection of samples.

Conflicts of Interest: The study was carried out in accordance with the relevant guidelines and regulations. The authors declare no conflict of interests and any potential financial conflicts of interest that any of the authors may have.

\begin{tabular}{ll}
\multicolumn{2}{l}{ Abbreviations } \\
AS & $\begin{array}{l}\text { ankylosing spondylitis } \\
\text { spondyloarthritides; }\end{array}$ \\
mSASSS & modified Stoke Ankylosing Spondylitis Spinal Score \\
HLA-B27 & human leukocyte antigen B27 \\
MICA & major histocompatibility complex class I chain-related gene A \\
NKG2D & receptor natural killer group 2, member D \\
SNP & single nucleotide polymorphism \\
sMICA & soluble MICA
\end{tabular}

\section{References}

1. Taurog, J.D.; Chhabra, A.; Colbert, R.A. Ankylosing Spondylitis and Axial Spondyloarthritis. N. Engl. J. Med. 2016, 374, 2563-2574. [CrossRef]

2. Rezaiemanesh, A.; Abdolmaleki, M.; Abdolmohammadi, K.; Aghaei, H.; Pakdel, F.D.; Fatahi, Y.; Soleimanifar, N.; Zavvar, M.; Nicknam, M.H. Immune cells involved in the pathogenesis of ankylosing spondylitis. Biomed. Pharmacother. 2018, 100, 198-204. [CrossRef] [PubMed]

3. Dalbeth, N.; Gundle, R.; Davies, R.J.; Lee, Y.C.; McMichael, A.J.; Callan, M.F. CD56bright NK cells are enriched at inflammatory sites and can engage with monocytes in a reciprocal program of activation. J. Immunol. 2004, 173, 6418-6426. [CrossRef] [PubMed]

4. Nielsen, N.; Pascal, V.; Fasth, A.E.; Sundström, Y.; Galsgaard, E.D.; Ahern, D.; Andersen, M.; Baslund, B.; Bartels, E.M.; Bliddal, H.; et al. Balance between activating NKG2D, DNAM-1, NKp44 and NKp46 and inhibitory CD94/NKG2A receptors determine natural killer degranulation towards rheumatoid arthritis synovial fibroblasts. Immunology 2014, 142, 581-593. [CrossRef]

5. Pridgeon, C.; Lennon, G.P.; Pazmany, L.; Thompson, R.N.; Christmas, S.E.; Moots, R.J. Natural killer cells in the synovial fluid of rheumatoid arthritis patients exhibit a CD56bright, CD94bright, CD158negative phenotype. Rheumatology 2003, 42, 870-878. [CrossRef] [PubMed]

6. Pollock, R.A.; Chandran, V.; Pellett, F.J.; Thavaneswaran, A.; Eder, L.; Barrett, J.; Rahman, P.; Farewell, V.; Gladman, D.D. The functional MICA-129 polymorphism is associated with skin but not joint manifestations of psoriatic disease independently of HLA-B and HLA-C. Tissue Antigens 2013, 82, 43-47. [CrossRef]

7. Kim, T.-J.; Lee, S.-J.; Cho, Y.-N.; Park, S.-C.; Jin, H.-M.; Kim, M.-J.; Park, D.-J.; Kee, S.-J.; Lee, S.-S.; Park, Y.-W. Immune cells and bone formation in ankylosing spondylitis. Clin. Exp. Rheumatol. 2012, 30, 469-475.

8. Szanto, S.; Aleksza, M.; Mihály, E.; Lakos, G.; Szabo, Z.; Végvári, A.; Sipka, S.; Szekanecz, Z. Intracytoplasmic cytokine expression and $\mathrm{T}$ cell subset distribution in the peripheral blood of patients with ankylosing spondylitis. J. Rheumatol. 2008, 35, 2372-2375. [CrossRef]

9. Conigliaro, P.; Scrivo, R.; Valesini, G.; Perricone, R. Emerging role for NK cells in the pathogenesis of inflammatory arthropathies. Autoimmun. Rev. 2011, 10, 577-581. [CrossRef] 
10. Vivier, E.; Tomasello, E.; Baratin, M.; Walzer, T.; Ugolini, S. Functions of natural killer cells. Nat. Immunol. 2008, 9, 503-510. [CrossRef]

11. 1Zitti, B.; Bryceson, Y.T. Natural killer cells in inflammation and autoimmunity. Cytokine Growth Factor Rev. 2018, 42, 37-46.

12. Tian, Z.; Gershwin, M.E.; Zhang, C. Regulatory NK cells in autoimmune disease. J. Autoimmun. 2012, 39, 206-215. [CrossRef] [PubMed]

13. Flodstrom-Tullberg, M.; Bryceson, Y.T.; Shi, F.D.; Hoglund, P.; Ljunggren, H.G. Natural killer cells in human autoimmunity. Curr. Opin. Immunol. 2009, 21, 634-640. [CrossRef] [PubMed]

14. Perricone, R.; Perricone, C.; De Carolis, C.; Shoenfeld, Y. NK cells in autoimmunity: A two-edg'd weapon of the immune system. Autoimmun. Rev. 2008, 7, 384-390. [CrossRef]

15. Gianchecchi, E.; Delfino, D.V.; Fierabracci, A. NK cells in autoimmune diseases: Linking innate and adaptive immune responses. Autoimmun. Rev. 2018, 17, 142-154. [CrossRef] [PubMed]

16. Lunemann, A.; Lunemann, J.D.; Munz, C. Regulatory NK-cell functions in inflammation and autoimmunity. Mol. Med. 2009, 15, 352-358. [CrossRef]

17. Lo, C.K.C.; Lam, Q.L.K.; Sun, L.; Wang, S.; Ko, K.-H.; Xu, H.; Wu, C.-Y.; Zheng, B.-J.; Lu, L. Natural killer cell degeneration exacerbates experimental arthritis in mice via enhanced interleukin-17 production. Arthritis Rheum. 2008, 58, $2700-2711$. [CrossRef] [PubMed]

18. Stojanovic, A.; Correia, M.P.; Cerwenka, A. The NKG2D/NKG2DL Axis in the Crosstalk Between Lymphoid and Myeloid Cells in Health and Disease. Front. Immunol. 2018, 9, 827. [CrossRef]

19. Bauer, S.; Groh, V.; Wu, J.; Steinle, A.; Phillips, J.H.; Lanier, L.L.; Spies, T. Activation of NK cells and T cells by NKG2D, a receptor for stress-inducible MICA. Science 1999, 285, 727-729. [CrossRef]

20. Babic, M.; Romagnani, C. The Role of Natural Killer Group 2, Member D in Chronic Inflammation and Autoimmunity. Front. Immunol. 2018, 9, 1219. [CrossRef]

21. Chen, D.; Gyllensten, U. MICA polymorphism: Biology and importance in cancer. Carcinogenesis 2014, 35, 2633-2642. [CrossRef]

22. Yang, X.; Kuang, S.; Wang, L.; Wei, Y. MHC class I chain-related A: Polymorphism, regulation and therapeutic value in cancer. Biomed. Pharmacother. 2018, 103, 111-117. [CrossRef] [PubMed]

23. Shi, C.; Li, H.; Couturier, J.P.; Yang, K.; Guo, X.; He, N.; E Lewis, R.; Zhou, X. Allele Specific Expression of MICA Variants in Human Fibroblasts Suggests a Pathogenic Mechanism. Open Rheumatol. J. 2015, 9, 60-64. [CrossRef]

24. Wang, Q.; Zhou, X. Associations of MICA Polymorphisms with Inflammatory Rheumatic Diseases. Open Rheumatol. J. 2015, 9, 94-100. [CrossRef]

25. Zhou, X.; Wang, J.; Zou, H.; Ward, M.M.; Weisman, M.H.; Espitia, M.G.; Xiao, X.; Petersdorf, E.; Mignot, E.; Martin, J.; et al. MICA, a gene contributing strong susceptibility to ankylosing spondylitis. Ann. Rheum. Dis. 2014, 73, 1552-1557. [CrossRef]

26. Evans, D.M.; A Spencer, C.C.; Pointon, J.J.; Su, Z.; Harvey, D.; Kochan, G.; Oppermann, U.; Dilthey, A.; Pirinen, M.; A Stone, M.; et al. Interaction between ERAP1 and HLA-B27 in ankylosing spondylitis implicates peptide handling in the mechanism for HLA-B27 in disease susceptibility. Nat. Genet. 2011, 43, 761-767. [CrossRef]

27. Van der Linden, S.; Valkenburg, H.A.; Cats, A. Evaluation of diagnostic criteria for ankylosing spondylitis. A proposal for modification of the New York criteria. Arthritis Rheum. 1984, 27, 361-368. [CrossRef]

28. Creemers, M.C.; Franssen, M.J.; van't Hof, M.A.; Gribnau, F.W.; van de Putte, L.B.; van Riel, P.L. Assessment of outcome in ankylosing spondylitis: An extended radiographic scoring system. Ann. Rheum. Dis. 2005, 64, 127-129. [CrossRef] [PubMed]

29. Wang, C.-M.; Ho, H.-H.; Chang, S.-W.; Wu, Y.-J.J.; Lin, J.-C.; Chang, P.-Y.; Wu, J.; Chen, J.-Y. ERAP1 genetic variations associated with HLA-B27 interaction and disease severity of syndesmophytes formation in Taiwanese ankylosing spondylitis. Arthritis Res. Ther. 2012, 14, R125. [CrossRef]

30. Li, Z.; Groh, V.; Strong, R.K.; Spies, T. A single amino acid substitution causes loss of expression of a MICA allele. Immunogenetics 2000, 51, 246-248. [CrossRef] [PubMed]

31. Lin, Z.; Bei, J.-X.; Shen, M.; Li, Q.; Liao, Z.; Zhang, Y.; Lv, Q.; Wei, Q.; Low, H.-Q.; Guo, Y.-M.; et al. A genome-wide association study in Han Chinese identifies new susceptibility loci for ankylosing spondylitis. Nat. Genet. 2011, 44, 73-77. [CrossRef]

32. Cortes, A.; Hadler, J.; Pointon, J.P.; Robinson, P.C.; Karaderi, T.; Leo, P.; Cremin, K.; Pryce, K.; Harris, J.; Lee, S.; et al. Identification of multiple risk variants for ankylosing spondylitis through high-density genotyping of immune-related loci. Nat. Genet. 2013, 45, 730-738.

33. Reveille, J.D.; Sims, A.M.; Danoy, P.; Evans, D.M.; Leo, P.; Pointon, J.J.; Jin, R.; Zhou, X.; Bradbury, L.A.; Appleton, L.H.; et al. Genome-wide association study of ankylosing spondylitis identifies non-MHC susceptibility loci. Nat. Genet. 2010, 42, 123-127.

34. Choy, M.K.; Phipps, M.E. MICA polymorphism: Biology and importance in immunity and disease. Trends Mol. Med. 2010, 16, 97-106. [CrossRef]

35. Zou, Y.; Stastny, P. Role of MICA in the immune response to transplants. Tissue Antigens 2010, 76, 171-176. [CrossRef]

36. Wensveen, F.M.; Jelencic, V.; Polic, B. NKG2D: A Master Regulator of Immune Cell Responsiveness. Front. Immunol. 2018, 9, 441. [CrossRef] [PubMed]

37. Isernhagen, A.; Malzahn, D.; Bickeboller, H.; Dressel, R. Impact of the MICA-129Met/Val Dimorphism on NKG2D-Mediated Biological Functions and Disease Risks. Front. Immunol. 2016, 7, 588. [CrossRef] 
38. Isernhagen, A.; Malzahn, D.; Viktorova, E.; Elsner, L.; Monecke, S.; Von Bonin, F.; Kilisch, M.; Wermuth, J.M.; Walther, N.; Balavarca, Y.; et al. The MICA-129 dimorphism affects NKG2D signaling and outcome of hematopoietic stem cell transplantation. EMBO Mol. Med. 2015, 7, 1480-1502. [CrossRef] [PubMed]

39. Isernhagen, A.; Schilling, D.; Monecke, S.; Shah, P.; Elsner, L.; Walter, L.; Multhoff, G.; Dressel, R. The MICA-129Met/Val dimorphism affects plasma membrane expression and shedding of the NKG2D ligand MICA. Immunogenetics 2016, 68, 109-123. [CrossRef]

40. Zingoni, A.; Vulpis, E.; Cecere, F.; Amendola, M.G.; Fuerst, D.; Saribekyan, T.; Achour, A.; Sandalova, T.; Nardone, I.; Peri, A.; et al. MICA-129 Dimorphism and Soluble MICA Are Associated With the Progression of Multiple Myeloma. Front. Immunol. 2018, 9, 926. [CrossRef] [PubMed]

41. Hughes, E.; Collins, R.; Kondeatis, E.; Wallace, G.; Graham, E.; Vaughan, R.; Stanford, M. Associations of major histocompatibility complex class I chain-related molecule polymorphisms with Behcet's disease in Caucasian patients. Tissue Antigens 2005, 66, 195-199. [CrossRef]

42. Munoz-Saa, I.; Cambra, A.; Pallarés, L.; Espinosa, G.; Juan, A.; Pujalte, F.; Matamoros, N.; Mila, J.; Julià, M.R. Allelic diversity and affinity variants of MICA are imbalanced in Spanish patients with Behcet's disease. Scand. J. Immunol. 2006, 64, 77-82. [CrossRef]

43. Cortes, A.; Gladman, D.; Raychaudhuri, S.; Cui, J.; Wheeler, L.; Brown, M.A. Imputation-based analysis of MICA alleles in the susceptibility to ankylosing spondylitis. Ann. Rheum. Dis. 2018, 77, 1691-1692. [CrossRef] [PubMed]

44. Tan, S.; Wang, R.; Ward, M.M. Syndesmophyte growth in ankylosing spondylitis. Curr. Opin. Rheumatol. 2015, 27, 326-332. [CrossRef]

45. Boukouaci, W.; Al-Daccak, R.; Dulphy, N.; Lauden, L.; Amokrane, K.; Fortier, C.; Marzais, F.; Bennabi, M.; de Latour, R.P.; Socie, G.; et al. Soluble MICA-NKG2D interaction upregulates IFN-gamma production by activated CD3-CD56+ NK cells: Potential impact on chronic graft versus host disease. Hum. Immunol. 2013, 74, 1536-1541. [CrossRef] [PubMed]

46. Mariaselvam, C.M.; Boukouaci, W.; Charron, D.; Krishnamoorthy, R.; Tamouza, R.; Misra, D.P.; Negi, V.S. Association of MICA129 polymorphism and circulating soluble MICA level with rheumatoid arthritis in a south Indian Tamil population. Int. J. Rheum. Dis. 2018, 21, 656-663. [CrossRef] [PubMed]

47. Ashiru, O.; López-Cobo, S.; Fernández-Messina, L.; Pontes-Quero, S.; Pandolfi, R.; Reyburn, H.T.; Valés-Gómez, M. A GPI anchor explains the unique biological features of the common NKG2D-ligand allele MICA*008. Biochem. J. 2013, 454, 295-302. [CrossRef] [PubMed]

48. Ashiru, O.; Boutet, P.; Fernández-Messina, L.; Agüera-González, S.; Skepper, J.N.; Vales-Gomez, M.; Reyburn, H.T. Natural killer cell cytotoxicity is suppressed by exposure to the human NKG2D ligand MICA*008 that is shed by tumor cells in exosomes. Cancer Res. 2010, 70, 481-489. [CrossRef]

49. Clayton, A.; Mitchell, J.P.; Court, J.; Linnane, S.; Mason, M.D.; Tabi, Z. Human tumor-derived exosomes down-modulate NKG2D expression. J. Immunol. 2008, 180, 249-258. [CrossRef] [PubMed] 